WIDER Working Paper 2020/61

\title{
Special economic zones in Southern Africa
}

Is success influenced by design attributes?

Cornelius Dube, Wellington Matsika, and Gamuchirai Chiwunze* $^{*}$

May 2020 
Abstract: Special economic zones (SEZs) in Africa are generally regarded as underperforming relative to their peers in the rest of the world. This study focuses on the design features of the SEZ in Africa that may help explain this underperformance. Literature was reviewed to identify the key design attributes of SEZ programmes that could enhance their success. A case study of six Southern African countries-Mauritius, Namibia, South Africa, Tanzania, Zambia, and Zimbabwe-is then used to assess if these countries' SEZ programmes meet the ideal design features. The study finds that key design attributes are missing in these countries, hence creating problems in the implementation of SEZ programmes. More importantly, the study identifies lack of developed SEZ geographic areas, especially the requisite on-site and off-site infrastructure, with dedicated authorities to provide such infrastructure, as the main drawback for SEZ programmes in failing countries. The study recommends that countries should pay due attention to all the key design attributes of their SEZ programmes in order to enhance the success of the SEZs.

Key words: design attributes, geographic areas, implementation, infrastructure, special economic zones

JEL classification: E02, H54, L52

Acknowledgements: The authors would like to thank UN-WIDER for their support. They would also like to thank Dr Gibson Chigumira for his invaluable research guidance in the production of the paper. They are deeply grateful to the Zimbabwe Special Economic Zones Authority, especially Wilfred Motsi, Douglas Seravasingadi, and Belinda Chimudzi, for the indispensable information that assisted in preparation of the study. Invaluable contributions from participants during the Work-In-Progress meeting for this assignment, at the Sheraton Hotel, Pretoria, on 6 December 2019, are acknowledged. All errors and omissions are the authors' own.

* All authors: Zimbabwe Economic Policy Analysis \& Research Unit (ZEPARU), Harare, Zimbabwe; corresponding author: Cornelius Dube,dubec@zeparu.co.zw

This study has been prepared within the UNU-WIDER project Southern Africa - Towards Inclusive Economic Development (SA-TIED).

Copyright (C) UNU-WIDER 2020

Information and requests: publications@wider.unu.edu

ISSN 1798-7237 ISBN 978-92-9256-818-4

https://doi.org/10.35188/UNU-WIDER/2020/818-4

Typescript prepared by Ayesha Chari.

The United Nations University World Institute for Development Economics Research provides economic analysis and policy advice with the aim of promoting sustainable and equitable development. The Institute began operations in 1985 in Helsinki, Finland, as the first research and training centre of the United Nations University. Today it is a unique blend of think tank, research institute, and UN agency — providing a range of services from policy advice to governments as well as freely available original research.

The Institute is funded through income from an endowment fund with additional contributions to its work programme from Finland, Sweden, and the United Kingdom as well as earmarked contributions for specific projects from a variety of donors.

Katajanokanlaituri 6 B, 00160 Helsinki, Finland

The views expressed in this paper are those of the author(s), and do not necessarily reflect the views of the Institute or the United Nations University, nor the programme/project donors. 


\subsection{Background}

Special economic zones (SEZs) can be defined based on their attributes (Zeng 2016). First, they can be defined as geographically designated areas, which could be physically secured, where economic laws are more liberal than in the rest of the country. In addition, SEZs can also be defined to include single-factory units, whereby one firm can be designated as an SEZ if considered strategic towards the country's development objective. Single-factory SEZs would also be entitled to the incentives normally enjoyed by those located in geographically designated areas. The application of liberal laws for SEZs would be designed as a tool to promote rapid economic growth by attracting investment and technology using fiscal and business incentives (Kinyondo et al. 2016). The liberal nature of the governing laws relates to labour, investment procedures and regulations, as well as land use (Zeng 2016). Usually, there is a dedicated administration or management that oversees operations in the designated area. This allows firms in the areas to get more efficient services, which include fast-tracked licensing and registration as well as more efficient customs procedures. There are also incentives to investors' operations within the delineated area which others outside these areas would not enjoy. The incentives include tax incentives, customs duty, capital freedoms, subsidies, and streamlined licensing and operation procedures that are more favourable. To attract setting up of facilities, SEZs often have better and more reliable infrastructure (roads, power, and water), which would not be comparable to what the domestic economic environment could afford for operations outside this area (Zeng 2016).

SEZs go by different names in different countries, either broadly or narrowly defined depending on their focus. They can be referred to as free zones, export processing zones (EPZs), or industrial parks (UNCTAD 2019). However, despite the different names, SEZs are generally underpinned by a belief in the economics of agglomeration. They are virtually government policies that are designed to usher or direct firms to locate in certain policy-induced advantageous areas. Agglomeration creates productivity spillover benefits, as firms locate close to other producers, suppliers of raw materials, and customers, thereby reducing transportation, search, and transactional costs (Newman and Page 2017). First, by being in close geographical proximity to suppliers and customers, firms in SEZs face low transportation costs for outputs and inputs. Second, by having firms that specialize in similar products operating together, technological transfer and diffusion is promoted, which results in production efficiencies (Kinyondo et al. 2016). Third, the fiscal incentives and enabling infrastructure provided can lead to firms facing lower production costs, which can also allow them to become competitive in the domestic and international market.

There is a general belief worldwide that SEZs are critical, as demonstrated by the increase in the number of countries and geographical areas that are being assigned the SEZ status. The number of SEZs grew tremendously from 176 in 46 countries in 1997 to 3,500 in 130 countries in 2007 (Boyenge 2007). In 2017, it was estimated that there were about 4,300 SEZ areas (World Bank 2017).

The proliferation of SEZs is associated with the developmental impact they have in the countries or regions in which they are implemented. Empirically, agglomeration benefits have been tested and established, even in developing countries. In a study of manufacturing firms in Tunisia, Ayadi and Mattoussi (2014) established a positive and significant effect on the growth of employment as a result of firms locating in the Greater Tunis area. They established that productivity growth was also associated with location in littoral governorates, which could be attributed to the better 
economic incentives offered to firms located in central business districts which, in turn, created productivity spillovers. Using panel data of Ethiopian manufacturing firms, Siba et al. (2012) found a positive relationship between the agglomeration of firms producing a given product in a location and the physical productivity of firms in the location due to positive externalities arising from agglomeration.

However, the implementation of SEZs has yielded a mixed bag of results and this has prompted the need for examining their influence on development. Kolko and Neumark (2009) noted that fiscal incentives offered in SEZs do not promote employment. This would imply that fiscal incentives reduce the tax base and budget revenues without significant overall benefit at the country level (Sinenko and Mayburov 2017). In Africa, the success of SEZs in attracting foreign direct investment (FDI), increasing exports, creating jobs, generating spillover effects to the rest of the economy, and fostering linkages with local firms has been very limited, despite some SEZs being in operation for over 10 years (Newman and Page 2017; Farole 2011).

The World Bank (2017) noted a general consensus that SEZs have the power to bring new businesses and FDI as well as to boost exports, but their power to increase employment and create spillover effects to the broader economy is subject of contention in the literature. Newman and Page (2017) also noted that African SEZs had limited success in employment creation with the exception of Lesotho. They further noted limited linkages between firms operating in SEZs and local firms outside the SEZs.

These limited achievements from the implementation of SEZs question the effectiveness of SEZs as a policy instrument that can help create employment and positive spillover effects to the broader economy. This study seeks to explore the contextual factors that determine the effectiveness of SEZs as a policy instrument to create employment and foster linkages between firms located in the SEZs and local firms outside the SEZs. The study motivation is that the success of SEZs is mainly dependent on the design of the programme. This implies that while many countries have been quick to adopt SEZs, they might not have paid attention to all the critical areas needed to ensure that the SEZs become successful. Ignoring a critical issue within the design of the SEZ programme prevents realization of the maximum benefits from the SEZ. Thus, this study was undertaken to identify the key attributes of successfully designed SEZ programmes and assess whether these attributes are in place in select African countries.

This study undertakes a comparative analysis of the design of SEZ programmes across Southern Africa to understand whether the success or failure being reported in literature is due to some design factors. The study will also inform policy makers in Southern Africa on how to ensure that design attributes of the SEZ regimes are given more attention so as to unlock the envisaged SEZ benefits.

\subsection{Study objectives}

Broadly, the objective of the study is to explore the contextual factors that determine the effectiveness of SEZs as a policy instrument. The specific objectives of the study include the following:

- to explore the key success factors for SEZ;

- to assess the various SEZ models that have been adopted in select Southern African countries;

- to identify the shortcomings of the models and how these can explain why SEZs have not been very successful; and 
- to proffer some recommendations on how the SEZ regimes can be made effective in Southern Africa.

\subsection{Methodology}

This study is premised on the hypothesis that the reason why SEZs have not been overly successful in some countries in Southern Africa is that they were not properly designed. While many countries have been quick to adopt SEZs, they might not have paid attention to all the critical aspects needed to ensure that the SEZs become successful. To explore this hypothesis, the study takes a case study approach of select countries in Southern Africa, blending literature review with an assessment of the provisions of the different legal and institutional frameworks governing SEZs.

The study, therefore, focuses only on design attributes. It looks at the design frameworks for the countries and then assesses how these frameworks compare with the ideal framework built up from literature review. The study does not go into detailed specific operational realities on the ground beyond the design attributes.

Literature review was conducted to understand the evolution and success factors of SEZs. Literature review enabled the identification of a possible range of key success factors that promote the growth and development of sustainable SEZ programmes. Based on this, six countries that have developed SEZs in Southern Africa were identified and their SEZ models assessed to check whether they meet the identified attributes. The ability to meet the desired attributes was used as the assessment basis.

The six case study countries are Mauritius, Namibia, South Africa, Tanzania, Zambia, and Zimbabwe. These were identified and selected mainly based on the availability of published information about structure and experiences of SEZs. Botswana was also assessed, but the SEZ regime is still at design stage and was eventually omitted from the report. Primary data were only limited to Zimbabwe due to budgetary constraints. The Zimbabwe Special Economic Zones Authority (ZIMSEZA) was engaged to understand the specifics with respect to SEZs in Zimbabwe.

\section{$2 \quad$ Key attributes of a successful SEZ programme}

Several desired attributes are expected to positively influence an SEZ programme. UNCTAD (2019) classifies the key success factors of SEZs into three groups: organizational, economic, and physical/spatial factors. The organizational factors relate mainly to issues centred on the manner in which institutions involved in the SEZ implementation are structured. The economic factors relate to those that are bound to affect the performance of the SEZ and its impact in the economy. Physical or spatial factors mainly relate to the location of the SEZ as well as on-site and off-site infrastructure.

\subsection{Key organizational factors}

\section{Alignment to the national vision and strategy}

There has to be robust economic rationale for establishing an SEZ programme. The first step is to ensure that SEZ development is a policy tool for addressing identified economic challenges. The appropriateness of the SEZ programme should be decided on early, so that political support is secured throughout the development of the programme. There should be an evidence-based 
business case as to why the SEZ programme is the appropriate policy intervention. The rationale for the SEZ programme should be linked to the existence of factors that are constraining economic activity in the country (COMCEC 2017).

As a result, the selected type of SEZ model should be appropriate and aligned to the national or regional policy objectives and targets. SEZs are more successful when they are designed in a way that their main components align to the national economic development strategy. Thus, there should be clear and quantified economic strategic priorities and performance outcomes in the national strategy that are best served by the SEZ programme.

In Malaysia, the success of the free industrial zone in Penang is partly attributed to its clear linkage with the national objectives targeting investment in the industry. This helped in securing political support and increased investor confidence in choosing Penang as an investment destination (COMCEC 2017).

\section{Political capital}

There is need for a politically stable environment that ensures smooth operation of business, reduces uncertainties, and attracts high-visibility foreign investment that act as anchor tenants to the zones. When decision making on issues relating to SEZ development is the responsibility of a single government ministry or agency/authority, the SEZ programme's success tends to suffer from lack of political support and direction (COMCEC 2017). Although the SEZ programme may be led by a particular government ministry or agency, it has to secure the involvement, support, and buy-in of other government ministries/agencies to facilitate the effective delivery of the SEZ programme. An SEZ working group or similar structure can serve as a good tool to secure support from all relevant stakeholders. It also ensures that a full range of issues and opportunities are captured in the SEZ programme to facilitate effective development of the SEZs.

Farole et al. (2013: 36) suggested that a suitable SEZ working group should have the following:

- at least one political and policy 'power-broker' or 'insider', for instance (but not necessarily) from the office of the Head-of-State or Head-ofGovernment; ${ }^{1}$

- at least one relatively successful representative of the private sector, actually engaged in business as opposed to simply on the executive of a chamber of commerce, and engaged in a competitive market (as opposed to a monopolistic or oligarchic one); [and]

- at least one senior, seasoned Civil Service technocrat (ideally at the Cabinet or Permanent Secretary level), in (or retired from) a Ministry interacting with business, accustomed to confronting the limits of what Government actually can and cannot accomplish.

\section{Legal and regulatory framework.}

The provision of a distinct regulatory and institutional framework different from what normally applies in the broader national or subnational economy is one of the key attributes of successful economic zones. SEZ-specific rules have been identified as having positive outcomes to zone users because they offer certain benefits and privileges not available outside the zones. The legal

\footnotetext{
${ }^{1}$ This helps to demonstrate that the SEZ programme is an executive priority and, therefore, effective administration of the programme is a priority
} 
or regulatory framework of the SEZ programme can be a law, or regulations, which can result from amendments of already existing legislative frameworks.

The legal and regulatory framework of successful SEZ programmes genuinely creates an operating environment that is distinct from the rest of the economy of the country. According to Farole (2011), for SEZs to be successful, policymakers need to work closely with the private sector in the light of changing needs to foster investor confidence by encouraging policy transparency and predictability. As there is a strong correlation between the investment climate variables and SEZ outcomes (Farole 2011), the legal and institutional framework governing SEZs is a critical determinant of success for SEZs because it ensures predictability and eliminates policy reversal fears.

A clear institutional and administrative framework must be well defined in the law, where the role of different government departments or agencies is strictly laid out. The oversight of the SEZ programme must be defined. If a board is responsible for the oversight, then the responsibilities and make-up of the board should be defined as well in the legal and regulatory framework. COMCEC (2017) noted that the most successful SEZs within the Organisation of Islamic Cooperation member countries have established new institutions responsible for regulating, operating, and developing SEZs.

A single overarching authority that manages multiple SEZs in a country is advantageous because it avoids the pitfalls of multiple authorities competing with each other, thereby creating investor confusion. The legal and regulatory framework should have a clearly defined process for designating, developing, and operating the SEZs. For example, it should be clear who designates an SEZ, who qualifies to apply for designation, and what are the processes followed for an area to be successfully designated.

The SEZ legal and regulatory framework should be aligned to the domestic and regulatory environment so that it does not create unnecessary distortions in national trading or the legal environment. For example, when an SEZ targets sectors that are already existing in the country, there is need to avoid creating perceptions that the SEZ programme unduly favours new investors at the expense of existing ones. Thus, SEZs should clearly target value-chain segments that are missing or underdeveloped.

The legal and regulatory framework should reduce administrative burden, cost, and time for investing in the SEZ compared with investing in the domestic environment. This will lead to increased investment in the SEZ. A one-stop-shop, which houses all the legal and regulatory issues to be complied with, is usually a common tool for reducing the compliance burden. Its purpose is to reduce administrative burden, costs, and time for investing.

When establishing the one-stop-shop it is important that the range of functions, activities, and services are clearly defined and agreed upon. These functions, services, and activities (e.g. licensing, permits) are usually controlled by various government entities. Therefore, there is need to agree on the mechanisms for passing on the control of these functions, services, and activities to the one-stop-shop. This could entail either having physical presence of officials from these various government officials or having an e-enabled and integrated system where information is shared, and decision making is done on a real-time basis. This is also why buy-in into the SEZ idea from the different government departments and ministries is necessary. 


\section{Incentives framework}

Firms operating in SEZs usually enjoy certain fiscal benefits, such as a partial or complete exemption from paying corporate taxes for a specific period of time or the application of a reduced tax rate. Most SEZ laws provide for a special customs regime, eliminating or reducing tariffs on goods, plants, or machinery imported into the zone. This applies to items to be used exclusively inside the zone. In addition, there may be expedited and simplified customs procedures. Incentives take a number of forms, including tax holidays, which exempt investors from paying corporate income or other taxes, and capital cost allowances, whereby investors receive benefits related to their capital investments (OECD 2017).

Non-fiscal incentives that boost the ease of doing business are considered more important to investors than fiscal incentives. Investors need an efficient investment licensing and clearance process. Where possible, fiscal incentives should be standardized at the country level across all the zones to prevent unfair competition among the zones (i.e. race to the bottom). Such competition results in unsustainable incentive packages that undermine economic performance and value for money. Thus, the main distinction among competing zones should not be the fiscal incentives (COMCEC 2017). Incentive packages should also include 'sunset clauses' that limit the period to which firms enjoy tax benefits to avoid unsustainable guarantees of fiscal incentives.

\section{Zone development and operation}

There should be a clear understanding of responsibilities of zone development and operation. The organization responsible for developing the zone must see a return on capital as it is expensive to develop an SEZ. The development of an SEZ should take into account investor needs and requirements that are in line with the kind of business they do. Successfully operated zones provide efficient services to investors while making a financial return on the services provided.

The success of an SEZ is critically dependent on efficient coordination of relevant government institutions and administrative, legal, and regulatory policies. This is important for fostering an efficient business environment and attracting FDI.

\section{Involvement of the private sector in zone development and operation}

Successful SEZs tend to be those operated by the private sector, where the relationship between the private operator and the government regulator is clearly spelt out, positive, and open. This is mainly because government institutions given the mandate to develop infrastructure only partly develop the SEZ in terms of infrastructure requirements owing to financial constraints. However, the SEZ developed and operated by the private sector also tends to have high charges that often discourage investors. It is important that when the private sector developer is engaged, there be positive dialogue to align the private operator profit and revenue objectives with the public sector economic and social objectives of the SEZ (COMCEC 2017).

\subsection{Key economic success factors}

\section{Selection of sectors and activities}

The SEZ-targeted industry/sectors should be aligned to the comparative advantages of the country, region, or site of the SEZ. The selected sectors should take into account the labour force, skills, and training levels of the workforce; proximity and capacity of input suppliers; and access to preferential markets. The selection should also be based on economic policy objectives of the country and activities that add the most value to the vision and rationale of the SEZ programme. 
The selected activities should have clear backward and forward linkages with the domestic economy (COMCEC 2017).

\section{Linkages to the rest of the economy}

SEZs should not operate as enclaves; they should be linked to the national economy so that knowledge and technology spillovers are reaped. The sectoral composition of existing firms in and around the SEZ has a lot of relevance in the success of economic zones. In Macedonia, during the Yugoslav times, the Skopje economic zone used to house one of the largest bus manufacturers in the former Yugoslavia. In 2013, a Belgian bus manufacturer selected the zone as the location for its newest bus assembly plant to take advantage of existing infrastructure and cluster of firms already operating in the area (OECD 2017). In Malaysia, the government established the Penang economic zones in 1972 with the aim of attracting businesses and investment in industries. In proximity to the free trade zones, five industrial estates were developed in order to accommodate supportive and ancillary industries related to businesses and industrial activities (COMCEC 2017).

\section{Economic impact performance indicators}

There should be a clear vision from the beginning on the size and scope of the economic impact that the SEZ programme seeks to achieve. These economic impact indicators can be job creation, FDI, exports, contributions to the gross value of the economy, technology and skills transfer, and linkages to the local economy. SEZs can also have transformational impacts such as economic diversification and industrialization (COMCEC 2017).

\section{Investment promotion}

Successful SEZs are effective in investment promotion. Specific marketing strategies should promote the value proposition of SEZs to investors. There should be an institution specifically given the mandate by legislation to market and promote investors. Investment promotion activities should be effectively coordinated by entities responsible for the operation, development, or regulation of zones.

\subsection{Key physical/spatial factors}

\section{Proximity to transportation nodes}

More successful SEZs exploit pre-existing advantages such as transport- and trade-related infrastructure, which offers local and international connectivity. The location of the SEZ should not be based on political considerations but rather informed by economic and technical considerations. According to Farole (2011), the location of the zones plays an important role in the success of SEZs.

When location decision-making is determined by political rather than commercial or economic considerations, the relevant authorities handling SEZs fail to address infrastructure connectivity, labour skills, and supply access that ensue. Thus, most FDI are likely to shun these locations in favour of locations in which they can access quality infrastructure, deep labour markets, and knowledge spillovers. It is argued that if an economic zone is established with the objective of generating exports, then its proximity to ports and airports will be crucial, and, if the objective is to develop the manufacturing sector, then its proximity to a suitably educated labour force and raw materials will determine its success (Cheong 2018). 


\section{Investment in infrastructure}

The provision of quality infrastructure is essential for the success of economic zones. Farole (2011) noted that the infrastructure and administrative environment that firms in economic zones face matters, as this has a bearing on net production costs. The further away an economic zone is from its source of raw materials or export channels, the more likely the economic zone is set up for failure (Cheong 2018). Zeng (2016) highlighted that economic zones need not be divorced from other sectors of the economy, arguing that an enclave model of implementing economic zones will not succeed as they need to be built on a local comparative advantage and with linkages with local suppliers as part of their value chains. Thus, for the success of an SEZ there is need for a good working environment both inside and outside the zone to maintain connectivity between the zone and the local economy and its markets. Experience of SEZ development demonstrates a clear relationship between the economic performance of SEZs and the quality of hard and soft infrastructure.

\section{An overview of SEZ models in select Southern African countries}

Before an assessment is made concerning the extent to which the SEZ frameworks in the selected countries meet the desired attributes, a quick overview of the SEZ model in the six case study countries is given.

\subsection{South Africa}

South Africa has a total of about 15 actual and potential SEZs that have been identified. Out of these, seven are operational while three more have been designated as SEZs but are not yet operational. ${ }^{2}$ The remaining seven zones have pending applications for designation as SEZs.

SEZs in South Africa date back to 2000 when the Industrial Development Zone (IDZ) programme was introduced by the Department of Trade and Industry under the Manufacturing Development Act of 2000 (Nyakabawo 2014). As a result, from 2016, all existing IDZs became SEZs, while all new SEZs could only be established in line with the provisions of the Special Economic Zones Act 16 of 2014 (Government of South Africa 2014). When the SEZ regime was mainly characterized by IDZs, the location for the SEZs appeared to be mainly coastal areas (Table 1). As a result, provinces that have coastal regions tended to dominate. The Eastern Cape and KwaZulu Natal provinces had two SEZs each, whereas OR Tambo International Airport was the only inland IDZ in the country. However, following the policy reforms, more areas began to attract interest for SEZs, resulting in an increase in the number of applications for different locations within the country.

Table 1: SEZs in South Africa

\begin{tabular}{lccc}
\hline Name of SEZ & Province & Year designated & Year operator permit issued \\
\hline Coega Development Corporation & Eastern Cape & 2001 & 2007 \\
OR Tambo Airport & Gaunteng & 2002 & 2010 \\
East London & Eastern Cape & 2002 & 2007 \\
Richards Bay & KwaZulu Natal & 2002 & 2009 \\
Saldanha Bay & Western Cape & 2013 & 2013 \\
Dube TradePort & KwaZulu Natal & 2016 & 2017 \\
Maluti-a-Phofung & Free State & 2017 & - \\
Musina-Makhado & Limpopo & 2017 & 2018 \\
\hline
\end{tabular}

\footnotetext{
${ }^{2}$ That is as of December 2019.
} 


\begin{tabular}{lccc}
\hline Nkomazi & Mpumalanga & 2018 & - \\
Atlantis & Western Cape & 2018 & - \\
Wild Coast: Mthatha & Eastern Cape & - & - \\
Gauteng Science and High-Tech Hub & Gauteng & - & - \\
Tubatse & Limpopo & - & - \\
Bojanala & North West & - & - \\
Upington & Northern Cape & - & - \\
\hline
\end{tabular}

Note: '-' indicates that an SEZ has not been either designated or issued with a permit at the time of writing.

Source: SEZ Advisory Board (2018) and authors' compilation.

\subsection{Namibia}

SEZs in Namibia mainly exist in the form of EPZs, targeting mainly export promotion and are regulated by the Export Processing Zones Act 9 of 1995 (see Government of Namibia 1995). The EPZ regime in Namibia is defined to include a geographical area as well as single-factory units (or a group of single-factory units).

In addition to locating in any place of their choice as single-factory EPZs, enterprises have an option of either operating in industrial zones or parks developed by the Offshore Development Company (ODC) [now defunct and functions absorbed by the Namibia Industrial Development Agency (NIDA)] or the Walvis Bay EPZ Management Company (the only EPZ management company to date). In addition to the Walvis Bay EPZ, the ODC had developed five multi-purpose industrial parks as follows:

- $\quad$ in Oshikango, Helao-Nafidi Town near the Angola-Namibia northern borders as a way to support and boost cross-border trade with Angola;

- in the capital city Windhoek;

- in Ondangwa in the northern part of the country;

- at Katima Mulilo near the north-eastern borders with Zambia, Zimbabwe, and Botswana; and

- at Katwitwi in the Kavango region on the Angola-Namibia border. (Namibia Investment Centre et al., no date.)

However, a number of enterprises also obtained the EPZ status as single-factory units and operate in areas outside those developed by the ODC and Walvis Bay EPZ.

\subsection{Tanzania}

Tanzania has both the Special Economic Zones Act of 2006 [as amended by the Economic Zones Laws (Miscellaneous Amendments) Act of 2011] and the Export Processing Zones Act of 2002 as enabling legislations (see Government of Tanzania 2006, 2011). SEZs mainly exist in the form of EPZs, although there are measures towards the transition towards broad SEZs.

There are about 14 SEZs/EPZs that were registered by the Export Processing Zones Authority (EPZA) in 2018 (WTO 2019). These include five government-owned (Benjamin William Mkapa SEZ, Bagamoyo SEZ, Mtwara Freeport Zone, Hifadhi EPZ, and Kigoma SEZ) and nine privately owned and operated SEZs/EPZs (Kisongo EPZ, Kamal Industrial Estate, Global Industrial Park, Kigamboni SEZ Company Limited, Kilwa Business Park, Ming Xin Company Limited, Mkinga SEZ, Star City SEZ, and Vigor SEZ Company Limited). However, only four of these [Benjamin William Mkapa SEZ, Hifadhi EPZ, Kamal Industrial Estate (partially) and Kisongo EPZ] were operational at the time of writing, with the rest being at development stage. This generally implies that although the SEZ/EPZ regime was initiated in 2002 with the passage of the Export 
Processing Zones Act, the process of operationalizing the zones has not been very smooth based on the low number of functioning SEZs.

\subsection{Zambia}

Governed by the Zambia Development Agency Act of 2006, SEZs in Zambia are mainly implemented within the broad multi-facility economic zones (MFEZs) initiative (Government of Zambia 2006, 2007). The MFEZs were introduced to the Zambian government in 2005 by the Japanese government through the Japan International Corporation Agency. MFEZs, which focus on both export-oriented and domestic-oriented industries, are a blend of free trade zones, EPZs, and the industrial parks/zones concept (Zambia Development Agency, no date).

Currently, six areas have been successfully declared as MFEZs and/or industrial parks, namely, Chambishi, Lusaka East, Lusaka South, Lumwana, Ndola (Sub-Sahara Gemstone Exchange), and Roma Industrial Park. The Lusaka East MFEZ was the first MFEZ to be declared by the government in 2007 (World Bank 2016). It is also known as the Zambia-China Economic \& Trade Cooperation Zone (ZCCZ), and is the first Chinese overseas economic and trade cooperation zone established in Africa (World Bank 2016).

The Chambishi MFEZ is a sub-zone of ZCCZ that was opened in 2007 and is located in Zambia's Copperbelt Province, approximately $380 \mathrm{~km}$ north of Lusaka (Newman and Page 2017; UNDP 2015). Lusaka South MFEZ was established in 2010, and is a public sector-led initiative. The Lumwana MFEZ was established through a declaration order in 2010. It is anchored on the Lumwana mine area in Solwezi District in North Western Province. Due to lack of a proper feasibility study, the location of the MFEZ was also subject to revision after being gazetted due to security concerns and availability of mineral deposits at the proposed site (AllAfrica 2013).

The Roma Industrial Park, which is located about $20 \mathrm{~km}$ north-east of the Lusaka International Airport, is owned by private investors. The Sub-Sahara Gemstone Exchange Industrial Park is located in Ndola District on the Copperbelt Province of Zambia and was approved in June 2010.

\subsection{Mauritius}

Mauritius was the first African country to establish EPZs through the passage of the Export Processing Zones Act of 1970. Mauritius then came up with the concept of freeport zones in the early 1990s. Facilities were established at the port and airport under the Freeport Act of 1992 (see Sanspeur and Chellapermal 1996). The 1992 Act was repealed by the Freeport Act of 2001, which in turn was repealed by the existing legislation: the Freeport Act, 2004 (see Government of Mauritius 2004). Thus, SEZs exist in the form of EPZs, which were mainly single-factory units and freeport zones.

The Freeport Act of 2004 designates about 19 sites as freeport zones (Government of Mauritius 2004). Freeport zones are located close to existing airports and sea ports so that they can easily access markets and raw materials through air cargo and ships, respectively. Port Louis has docking and storage facilities that facilitate the importation and handling of large cargo imported through the sea. At the same time, Mauritius boasts of high freight maritime service rates, with the Port Louis Harbour serviced by a number of shipping lines. Freeport developers have built warehouses to rent out to licence holders within the freeport zones. 


\subsection{Zimbabwe}

SEZs in Zimbabwe are governed by the Special Economic Zones Act [Chapter 14:34] of 2016 (see Government of Zimbabwe 2016). ${ }^{3}$ There are generally two types of SEZs in Zimbabwe. A singlesector SEZ has only one type of goods or services to be produced or exported from within it, which can be done by either one firm or a number of licensed investors. A multi-sector SEZ has two or more goods or services being produced within it. SEZs can be either public or private. In a private SEZ, the developers or owners of land or premises with potential for designation as SEZs have to apply to ZIMSEZA for designation. In addition, companies already operating in Zimbabwe can also apply under the private SEZ category, where they can be conferred the SEZ status as single-factory units.

The public SEZ category exists in two formats. First, land owned by local authorities in areas that have been deemed suitable based on comparative and competitive advantages can be declared as an SEZ. However, this is government policy and it is the government that identifies such sites for ZIMSEZA to designate as SEZs. Second, as part of the SEZ programme, some areas have already been identified as pioneer SEZs that also serve as platforms for building expertise and experience on SEZ administration in Zimbabwe. These have been designated generally on state and local authority land after identification by the government. In addition, some SEZs are classified as public but also have some private sector players with title deeds to the land.

Several types of SEZs have been designated in Zimbabwe and these are at different stages of implementation. Single-factory SEZ status has been given to firms already invested in the country and these include a ferrochrome mining firm, Afrochine Smelting in Selous; a lithium mining firm, Arcadia Lithium in Goromonzi; a beverages manufacturing firm, Varun Beverages; a detergent manufacturer, Trade Kings Zimbabwe; and a medical manufacturer, Vislink Investments.

In addition, there are six geographic areas that have been designated as public SEZs: BelmontKelvin-Donnington-Westondale Corridor SEZ (Bulawayo), Imvumila SEZ (Bulawayo), Masuwe SEZ (Victoria Falls), Sunway City Pvt Ltd SEZ (Harare), Beitbridge SEZ (Beitbridge), and Fernhill SEZ (Mutare).

Among private sector SEZs is Nkonyeni Agricultural Hub SEZ, an agro-processing area where the private sector owns the land and applied for SEZ status.

\section{$4 \quad$ An assessment of how the countries meet the desired attributes}

As already explained, three main attributes are expected for a successful SEZ, namely, organizational, economic, and physical/spatial factors. These are assessed in turn for the case study countries in this section.

\subsection{Organizational factors}

\section{Alignment to the national vision}

SEZs are expected to work best when they are implemented as part of a national vision, which also enhances complimentary support and harmony with other programmes. A look across the six

\footnotetext{
${ }^{3}$ As of December 2019.
} 
countries shows that this is true with respect to South Africa. The SEZ regime in South Africa is part of its National Development Plan 2030, which identifies industrial zone development and trade promotion as a necessary intervention. SEZs became central in South Africa's Industrial Policy Action Plans, which are short-term policy strategies designed to implement the country's National Industrial Policy Framework.

The SEZ regime in South Africa is also implemented using a clear strategy. A clear policy framework for the development, operation, and management of SEZs in South Africa was developed in 2012 (Department of Trade and Industry 2012). The policy also provides for a smooth transition from the IDZ regime into an expanded SEZ regime. The policy facilitated the situation of the SEZ within the context of changing priorities at the national and regional economic development scenarios. This also enhances chances of SEZ success.

In Zambia, the MFEZs are also implemented as part of Zambia's Vision 2030 of attaining middleincome country status. The Vision 2030 strategy is implemented through a series of five-year national development plans, and it is in these development plans that MFEZs are considered central. However, although the MFEZs are aligned to the country's overall vision, there has not been a specific MFEZ strategy or policy that has been put in place to guide MFEZ implementation. This would have ensured that the implementation of the MFEZ is not just subsumed in the general investment promotion strategies. The absence of a clear MFEZ policy or strategy negatively affects the likelihood of success, as MFEZ initiatives can be easily overshadowed by other government programmes.

In Tanzania, there is no stand-alone vision or strategy for SEZs, which has seen the proliferation of SEZs in regions of the country being mainly politically driven, with each region pushing for an SEZ to be located in its locality (Kweka 2018). Due to lack of a guiding principle, the SEZs are not mainly being driven by comparative advantages or the need to address policy bottlenecks affecting economic development. As expected, the designation of SEZs in many parts of the country at one time has affected the progress in the development of SEZs, as government resources are thinly spread across all the SEZs. In addition, most of the SEZs in Tanzania were designated before a feasibility study was conducted, resulting in non-viable areas also being designated (Kweka 2018). Thus, this failure to meet one of the critical attributes for a successful SEZ programme is expected to weigh down chances of SEZ success in Tanzania.

When Mauritius adopted SEZs through the EPZ regime in 1970, it was part of the implementation of a new industrial policy focusing on export-oriented development. The EPZs were part of a programme to diversify the island's economy by encouraging industrial development and reducing dependence on sugar (Alter 1990). When the government expanded the SEZ regime in 2004 to include the freeport initiative, it was also part of the implementation of a broad policy to transform Mauritius into a major regional distribution, trans-shipment, and marketing centre. Thus, the SEZs were aligned to the country's national development plans at the time, which also enhanced their chances of success.

However, like Zambia, there was only legislation and regulations to back both the EPZ and the freeport initiatives in Mauritius, with no SEZ strategy or policy developed to guide how the programmes would be rolled out. The absence of a dedicated policy for the EPZ and the freeport would generally serve to reduce the effectiveness of the SEZ, especially when conflicting and competing needs arise.

There is also alignment of national development goals and the EPZ programme in Namibia. The EPZs are introduced as a mechanism to implement the industrial policy, which is anchored in the country's Vision 2030. The industrial policy provides for special incentives for manufacturing 
companies; export subsidies accompanied by the promotion and establishment of the EPZ regime. Having the EPZ programme implemented as part of the broad national vision development programmes enhances chances of success. Just like South Africa, Namibia also came up with the EPZ industrial development strategy, which is a step-by-step guide on Namibia's EPZ and the procedures to be followed (Government of Namibia, no date). The strategy is critical in facilitating the success of the SEZ regime.

In Zimbabwe, SEZs had been part of the policy discourse for a long time before they were eventually introduced. In 2009, special zones were identified as critical for the economic recovery under the first economic blueprint after hyperinflation, the Short-Term Emergency Recovery Programme. The medium-term plan, which was implemented between 2011 and 2013, also identified sectoral and economic zones as critical for the sustenance of the growth momentum that had been witnessed in the economy. This was also underlined by the Zimbabwe Agenda for Socio-Economic Transformation (2013-18), which provided for the introduction of SEZs in Zimbabwe.

However, there is no SEZ policy to guide the manner in which SEZs would be identified and implemented in Zimbabwe. As a result, while it is ZIMSEZA that has the power to designate, government also plays a significant role in identifying possible SEZ areas. This has resulted in many areas being identified, while there are no feasibility studies in place to inform the viability and compelling factors for designation.

\section{Legal and regulatory framework.}

Having a distinct regulatory and institutional framework normally ensures that there is focus on SEZs without undue dilution due to other obligations. Except for Zambia and Tanzania, generally all the other case study countries have ensured that they have dedicated legislations and regulatory bodies to oversee the implementation of the SEZ regime.

South Africa has a dedicated legislative framework in the form of the Special Economic Zones Act 16 of 2014 (Government of South Africa 2014) that focuses on SEZs, while the SEZ Advisory Board also serves as a dedicated regulatory oversight institution. However, under the IDZ regime, the legislative framework was the Manufacturing Development Act of 2000, which did not have a dedicated regulatory board for oversight. As a result, when the SEZ regime was characterized by IDZ only, the process of approval was very long, demonstrated by the period it took to get an operator's permit once the SEZ had been designated.

For example, four IDZs were designated in 2001 and 2002, but the permits for the zones to start operations were granted only between five and eight years later (Table 2). However, under the new regulatory environment, the approval process appears generally faster. The application for designation of the Musina-Makhado SEZ was brought to the SEZ Advisory Board in January 2016, and by December 2017, a final gazette notice had already been issued. In 2018, a permit had been granted to Shenzen Hoimor Resource Holding Company (Ltd) as the SEZ operator (SEZ Advisory Board 2018). The same is also true for Atlantis SEZ: the application for designation was brought before the SEZ Advisory Board in June 2017, and by June 2018, the application had already passed through the SEZ Advisory Board and approval for designation from the minister had been obtained. 
Table 2: Time frame between designation and permit issuance

\begin{tabular}{lcc}
\hline Name of SEZ & Year designated & Year operator permit issued \\
\hline Coega Development Corporation & 2001 & 2007 \\
OR Tambo Airport & 2002 & 2010 \\
East London & 2002 & 2007 \\
Richards Bay & 2002 & 2009 \\
Saldanha Bay & 2013 & 2013 \\
Dube TradePort & 2016 & 2017 \\
Musina-Makhado & 2017 & 2018 \\
Atlantis & 2018 & - \\
\hline
\end{tabular}

Note: '-' indicates that the operator permit has not been issued at the time of writing.

Source: authors' compilation.

Having multiple SEZs in a country can also create unnecessary competition for incentives resulting in 'a race to the bottom'. Thus, having a single regulatory authority with oversight over a number of SEZs is also considered positive in enhancing successful SEZ regimes. The SEZ Advisory Board has oversight over all the SEZs in the different areas of the country.

However in Zambia, the legal framework for SEZs is the Zambia Development Agency Act of 2006, which only has a section on MFEZs. The Multi-Facility Economic Zones (General) Regulations of 2007 had to be issued to ensure that the necessary provisions for the implementation of MFEZs are in place (see Government of Zambia 2006, 2007). Therefore, there is no stand-alone legislation to govern the SEZ regime, as the current legislation also incorporates other issues that might not necessarily have much to do with the MFEZs. This also implies that while the Zambia Development Agency (ZDA) is the institution responsible for SEZs under the Zambia Development Agency Act, it also has several other functions away from the MFEZs. Thus, the legal framework for SEZs in Zambia imposes some limitations on the success of the SEZ regime.

In Tanzania, there are still two legislations that are relevant in shaping the SEZ regime. EPZs in Tanzania are governed by the Export Processing Zones Act of 2002, while SEZs in general are governed by the Special Economic Zones Act of 2006 (see Government of Tanzania 2002, 2006). The Economic Zones Laws (Miscellaneous Amendments) Act of 2011 provides for an overarching authority, the EPZA, responsible for managing all the SEZs (see Government of Tanzania 2011). However, there are some weaknesses in the legislative framework. The SEZ legislative framework is not properly aligned to the East African Community Customs Area Act of 2004 (Kweka 2018). As a result, incentives offered under the SEZ programme are not recognized and they have not been effective. Thus, most firms operating in SEZs are only EPZ firms rather than broad SEZs focusing on the domestic market as well. This has affected the participation of local investors who have interest in the domestic market as opposed to the export market. For example, firms operating in the Benjamin William Mkapa SEZ are still operating as EPZ firms and have to export at least 80 per cent of their products (Kweka 2018).

The legal and regulatory framework for SEZs in Mauritius has always been clearly supported by the regulations that are distinct from what applies to non-EPZs and non-freeport areas. However, instead of having an oversight institution that is specifically focused on SEZs, the freeport SEZ regime has leveraged on an existing institution for oversight. The Board of Investment is established under the Investment Promotion Act and also caters for other investment promotion issues outside SEZs (see Government of Mauritius 2000). This implies that the mandate would be divided across different activities. However, for a small economy such as Mauritius, having harmonized regulatory frameworks has more advantages than disadvantages, as it allows investors to only deal with few authorities. 
There is a distinct legal framework in place in Namibia that only applies to EPZs and this regulatory framework is provided for by the Export Processing Zone Act of 1995. Regulatory oversight exists in the form of NIDA established by the Namibia Industrial Development Agency Act of 2016 (Government of Namibia 2016). This implies that there was no dedicated regulatory oversight between 1995 and 2016, which would be expected to affect performance.

SEZs in Zimbabwe are governed by the Special Economic Zones Act [Chapter 14:34] of 2016 (see Government of Zimbabwe 2016). Generally, the SEZ programme is still new, with most of the identified SEZ areas yet to be developed. The oversight of SEZs lies with the ZIMSEZA, which regulates all SEZs in Zimbabwe. Having a dedicated entity for SEZs has helped ensure that expertise is quickly built on how best the SEZ programme can be implemented in Zimbabwe.

\section{Incentive framework}

Having some incentives that only apply to firms in SEZs but cease to apply once the firms leave the zone is also positive in ensuring that SEZs becomes attractive. The incentive framework should also be standardized across all SEZs to avoid unfair competition. Generally, all the six countries have tried to make SEZs attractive by putting in place a range of tax incentives that ideally would help attract investors, provided other complimentary services and enablers are in place. However, in Zambia, the legislative framework does not specify the incentives that are available to the MFEZ investors. As a result, the incentive framework is unstable and unpredictable for investors. For example, the zone management for Chambishi MFEZ identified changes in government incentives for the zone developer and zone companies as being one of the challenges with the MFEZ regime in Zambia (UNDP 2015). The absence of a clear and predictable incentive structure that is part of legislation is a weakness for Zambia's SEZ regime.

\section{Zone development and operation responsibility}

A critical issue with respect to the development of SEZs is the presence of clear responsibilities on who develops and operates the zones. The framework should give an incentive for the operator to provide efficient services to investors while making a financial return from the services provided. This implies that having the government as the operator would be expected to result in limitations, as return on investment would not be a primary motivation. Countries such as South Africa, Namibia, and Mauritius have ensured that the responsibility to develop and operate the SEZ is separate from regulatory roles. In other words, it is not the regulator that is also bestowed with zone development functions. However, the other remaining countries have adopted hybrid approaches where the regulator is also involved in the development and operation of the zones.

In South Africa, each zone has in place an SEZ board with a chief executive officer, who in turn should appoint an SEZ operator to develop, operate, and manage that SEZ on behalf of the SEZ board. This means that it is the operator who has to ensure that there is enabling infrastructure as well as access to all the critical services needed within the zone. In Mauritius, the roles for development and operation of the SEZs are clearly defined by the Investment Promotion Act as well as the Freeport Act (see Government of Mauritius 2000, 2004). The role of the freeport developer and freeport operators is clearly specified and separate from the regulatory functions. In Namibia, the developer roles are only given to one institution: the EPZ management company, which is expected to provide and maintain such amenities and services in EPZs as necessary. NIDA has not been given SEZ development roles.

However, Zambia and Tanzania have also embedded zone development and regulatory roles into the institutions that oversee the implementation of SEZs. The development of an area into an MFEZ in Zambia is the responsibility of both the ZDA as well as any interested investors. Having 
ZDA, a government institution, as the developer subjects development of the SEZs to the various funding constraints that characterize public institutions. The relationship between the developer and the regulator after developing the MFEZ is also not clearly specified by the legislation. Like Zambia, in Tanzania the EPZA is a zone developer and operator, but with the option of either operating the zone or subcontracting the operation to a zone management company that manages the zone on its behalf.

In Zimbabwe, the Special Economic Zones (General) Regulations of 2018 were issued to provide for roles for developers and operators in the SEZs. Developers and operators have to apply to be licensed by ZIMSEZA in order to perform the development and operation functions. However, there are public SEZs, where the government still has a responsibility for developing the zones. This arrangement is already proving difficult, as all the public SEZs are yet to be developed. Thus, declaring an SEZ without having already identified private operators and developers limits the success of the SEZ.

\subsection{Economic factors}

\section{Selection of sectors and activities}

The success of an SEZ is also dependent on whether or not the sectors and activities within the SEZ have been arbitrarily selected without any compelling factors. A country in which all the SEZs have been chosen based on applications or requests for detailed justifications before their declarations is more likely to succeed in SEZ implementation.

The South Africa SEZ regime puts the onus on the applicant to justify why the area has to be declared an SEZ. Among the requirements it is necessary to demonstrate how declaration of the area as an SEZ would further the national government's industrial development objectives. The applicant needs to demonstrate that the proposed SEZ will facilitate the creation of an industrial complex with strategic national economic advantages for targeted investments. In addition, the applicant has to demonstrate how the SEZ will take advantage of existing industrial and technological capacity by promoting integration with local industry and increasing value-added production. ${ }^{4}$ The South African SEZ framework thus generally fulfils the attributes expected of a successful SEZ in terms of location advantages.

In Zambia, an area is declared an SEZ generally by the Minister for Industry and Trade, on the recommendation of the ZDA Board and after consultations with the Minister for Finance and the Cabinet. Where the declaration is made in response to an application by the private sector, the MFEZ General Regulations of 2007 state the factors that the ZDA Board considers for SEZ designation. These factors include local and foreign FDI levels, amount and quality of local employment creation, skills development and transfer to local entrepreneurs and communities, introduction and transfer of technology, extent of economic diversification, foreign exchange generation, import substitution, and utilization of preferential trade agreements. However, the existing MFEZs that were created through development assistance lack most of these desired attributes. The requirement for feasibility studies is also not explicit in the legislation.

Tanzania does not have a strict template, focusing more on justifiable grounds for declaring an area as an SEZ. Kweka (2018) raises concerns over how SEZ projects outlined in Tanzania's policy documents are prioritized. This implies that there may be limited use of evidence in the planning

\footnotetext{
${ }^{4}$ Section 23 of the Special Economic Zones Act 16 of 2014 (Government of South Africa 2014).
} 
and prioritization of the SEZ projects. This concurs with the observation by Farole (2011) who suggested that the designation of SEZ projects in Tanzania was politically determined.

For Mauritius, the emphasis on freeport zones seeks to promote exports, which include warehousing, sorting, grading, cleaning, labelling, and packing. As a result, all the zones are located either within the Port Luis area or Sir Seewoosagur Ramgoolam International Airport.

For Namibia, the designation of an area as an EPZ is the prerogative of the Minister of Trade and Industry in consultation with the Minister of Finance. The former can declare an area an EPZ, together with any delimitation in terms of boundaries and physical characteristics of the EPZ without responding to any application. Only in situations of single-factory unit EPZs will the minister declare a firm to be an EPZ in response to an application by the owner, with justifications.

In Zimbabwe, private SEZs are required to be based on application with justifiable reasons. Public SEZs can be declared by the government after considering the comparative and competitive advantages of the SEZ area. However, there are no detailed feasibility studies undertaken to inform the decision whether or not to designate an area as an SEZ.

\section{Investment promotion}

The responsibility for promoting and marketing SEZs is likely to be more effective if done by an SEZ developer or operator. This ensures that those areas that have not yet been developed are not unnecessarily marketed. Where this function is performed by the SEZ regulator, there is a tendency to focus more on investors rather than on development. Under the South Africa SEZ regime, the role of promoting the SEZ as an investment destination is given to the SEZ operator. This is done in consultation with the SEZ Advisory Board. Thus, there is an incentive for the operator to ensure that investors' concerns are quickly addressed.

In Zambia, the ZDA, which is the SEZ regulator, has also been given the responsibility to market the MFEZ in Zambia. However, the ZDA also has some other regulatory responsibilities outside SEZ. Among the concerns of investors is the fact that some of the MFEZs are marketed before completion of basic infrastructure or at a time when there is no one-stop-shop for sectoral approvals of zone companies (UNDP 2015). This implies that the marketing strategies to promote SEZs in Zambia can be improved by having SEZ-specific investment promotion institutions, as in South Africa.

In Tanzania, the EPZA has also been accused of over-hyping the SEZ programme, with negative effects on the programme (Farole 2011). Most of the SEZs are being marketed when land issues have not been resolved in the zones. In Mauritius, the Board of Investment is the focal point for all investment-related promotional and marketing activities. The board also happens to be the main oversight institution for the freeport zones as well as any remaining EPZs. The same is also true for Namibia, where NIDA is responsible for the promotion and marketing of all approved SEZs. In Zimbabwe, ZIMSEZA has the investment promotion role rather than the SEZ developers or operators.

\section{Single-factory units versus geographic areas}

Across the six countries, there are different SEZ regimes that have been adopted. South Africa and Zambia have maintained a regime where only geographically identified areas can be declared SEZs, whereas other countries have opted for a situation where even one firm can be given such status. Single-factory units would enjoy the benefits associated with the SEZ status, which could also ensure that they become more competitive and enhance their production and export capacity. 
However, single-factory units would not enjoy the economies of agglomeration, the privilege of access to sound infrastructure, and forward and backward linkages that would normally be associated with SEZ firms located in geographically demarcated areas. For example, by December 2016, the EPZA of Tanzania had issued 140 licenses of which 56 per cent were single-factory units (Kweka 2018). However, the SEZ regime was also notably characterized by limited technological transfer among SEZ firms, with little reliance on each other in terms of input and output sourcing, with weaker backward and forward linkages (Kinyondo et al. 2016).

Investment attraction is often given as the reason for establishing SEZs. However, where singlefactory units are accorded SEZ status, in most cases these would be firms already operational; hence, the SEZ status can be regarded as a bail out. In addition, the single-factory SEZ status does not bring in new investment if accorded to already existing firms. In Zimbabwe, Afrochine Smelting, Varun Beverages, and Trade Kings Zimbabwe are investments that came before the SEZ regime was instituted but got SEZ status. Thus, a single-factory SEZ regime is not likely to be effective. Single-factory SEZ regimes co-existing with geographic area SEZ regimes are found in Zimbabwe, Namibia, Tanzania, and Mauritius. However, in Mauritius, the freeport zone initiative has not been extended to single-factory units, which enjoyed such privilege during the EPZ era but is now being phased out.

\subsection{Physical/spatial factors}

\section{Proximity to transportation nodes}

SEZs that exploit pre-existing advantages such as transport- and trade-related infrastructure that offers local and international connectivity are more likely to be successful. If the SEZ industries are not in any way aligned to the comparative advantages of the country, strategically sited, or in proximity to input suppliers and markets, then the SEZ is likely to fail.

In South Africa, when the SEZ regime was mainly characterized by IDZs, the location for the SEZs was mainly coastal areas given that the focus was export promotion. Given that most of the operational SEZs at the moment are in coastal areas, the main motivation for designation is the need to increase exports. For example, Coega SEZ is adjoined to the Port of Ngqura, which is a deep-water harbour serving as a gateway to global markets. Saldanha Bay SEZ is at the Port of Saldanha, which is close to the global southern trade route. Dube Trade Port is also positioned between the two biggest sea ports in Southern Africa, and linked to the rest of Africa by road and rail. The Maluti-a-Phofung SEZ is strategically located on the Durban-Reef corridor. However, following policy reforms, more areas began to attract interest for SEZs, resulting in an increase in the number of applications from different locations within the country. However, trade advantages continue to be the compelling reason, even though this includes domestic trade as well. Thus, SEZs in South Africa are more likely to exploit the transportation nodes and succeed.

The same is also true for Zambia. The MFEZs are located either in proximity to Lusaka City or Lusaka International Airport or in mining trade zones, which makes them ideally suited to attract investors for ease of accessibility. However, while Roma Industrial Park, focusing on property development, is strategically located in proximity to the catchment area of Lusaka City, the Lusaka South MFEZ, which is within $10 \mathrm{~km}$ from Lusaka, was mainly motivated by the envisaged development of the Greater City of Lusaka. There are currently no clear backward and forward linkages in terms of the focus products for the zone and the availability of inputs or feeder throughput in Lusaka. This could explain why not many success stories from the zone have been published, although it was established in 2010. 
In Tanzania, there are concerns that the locations of SEZs may not be optimal to take advantage of strategic features of each location. This is supported by Farole (2011) who notes that for Tanzania the development of the EPZ and SEZ programmes was not informed by any evidencebased research to determine competitiveness, comparative advantages, optimal opportunities, and strategic positioning of the programmes. This makes it possible for most of the SEZ projects to lack the basic infrastructure required to attract investors.

The EPZ regime in Mauritius did not have a location advantage, as firms all over the country could be designated EPZ single-factory status. However, being a small economy, this did not create a lot of challenges as the firms merely took advantage of the existing infrastructure. However, the freeport zone initiative has strategically ensured that all the zones are in proximity of either air or sea transport routes to facilitate international trade. This enhances the chances of success.

In Namibia, the EPZs were mainly located in areas that were developed by the ODC, which mainly targeted border towns and ports (Walvis Bay). Thus, access to trade was the main driver in identifying EPZ locations. However, given that a number of EPZ firms are single-factory SEZs, they have faced challenges in accessing quality transport infrastructure, such as rail and shipping routes. Constant breakdown of railway infrastructure and failure to generate sufficient volumes have compelled some EPZ firms to rely on expensive alternative forms of transportation.

In Zimbabwe, a number of SEZs have been declared at geographic locations where there are no discernible advantages in terms of market access and transportation nodes. Transport infrastructure has not yet been developed to ensure that the identified areas are easily accessible. However, the six geographic areas that have been designated as public SEZs have mainly targeted urban areas (Bulawayo, Victoria Falls, Harare, Beitbridge, and Mutare) with road and railway networks, although the state of the infrastructure is still a problem.

\section{Investment in infrastructure}

Given that there is a clear relationship between the performance of SEZs and the quality of hard and soft infrastructure, a regime that facilitates the creation of the requisite infrastructure for an SEZ before firms invest in it stands to register success. A regime that declares an SEZ with little regard for how enabling infrastructure would be availed is likely to fail. Unfortunately, this is a common characteristic among SEZ regimes in some of the countries. By requesting for a standalone SEZ operator for each zone, responsible for ensuring that there is conducive infrastructure, the South Africa regime has gone a step ahead in ensuring that infrastructure provision does not remain a central government responsibility. In addition, by making available the SEZ Fund that can be tapped into for this objective, the regime further enhanced its probability of success.

The same is also true with respect to Mauritius. One of the key requirements for the developers is to ensure that there is conducive infrastructure to facilitate smooth operation of the zones. Failure to adequately maintain the zone will result in the revocation of the licence. Thus, there is a clear programme based on the legislation to confirm that there is an institution responsible for ensuring that both hard and soft infrastructure are in place. This is expected to go a long way in attracting investors into the zones.

Namibia has also tried to adopt a model that compels the development of infrastructure in the SEZ to attract investors. This applies to those SEZs that operate in geographically designated areas where EPZ management companies have been instituted. EPZ management companies are required to develop the EPZ and provide and maintain the necessary amenities and services, including streets, buildings for industrial or commercial purposes, water supply, sewerage system, and electricity or gas. The Walvis Bay SEZ is generally considered successful in this regard. 
However, a drawback is that the SEZ regime has also embraced single-factory units as SEZs, where supportive infrastructure does not exist. There are also no other successful arrangements outside Walvis Bay.

In Zimbabwe, the developer is expected to construct infrastructure and assets on SEZ land, including on-site infrastructure, transportation connections, employee quarters, office space, and other facilities for use by other regulators, including customs authorities. However, off-site infrastructure, especially water and electricity, will still be needed, which is not necessarily the responsibility of the developer. In addition, SEZ areas have been declared and already investors are being sought before the on-site and off-site infrastructure is in place. The operationalization of the SEZ is expected to take longer, thus undermining the achievement of set targets. For Zambia, the ZDA is responsible for developing the MFEZ but its capacity is constrained by funding. There are already many concerns about the poor state of infrastructure, which is affecting operations in some of the MFEZs. For example, when the Lusaka East MFEZ was developed, the government had promised to build off-site infrastructure, such as the power and water lines, but this was not fulfilled (World Bank 2016). All the zones are currently suffering from inadequate water, power, sewerage, transport logistics, and roads, which is affecting the increase of investment in the MFEZs. For example, the Lusaka East MFEZ management had to turn down many investors due to severe power problems. The MFEZ framework does not give precedence for infrastructure availability before investors are licensed to operate, which works unfavourably towards the success of the SEZs.

The provision of soft and hard infrastructure in SEZs in Tanzania is a challenge. Farole (2011) reported that in Tanzania there is poor infrastructure and operational performance at the ports negatively affects the competitiveness of the firms operating in the zones. Infrastructure and operational performance should be good on-site and off-site. Since most of the SEZs are singlefactory units, the efficient provision of dedicated hard and soft infrastructure is hampered. The smaller size of the single-unit SEZ may not justify the costs of providing dedicated infrastructure.

\section{Conclusion: Implications based on the design attributes}

Based on the assessment in this paper, it is quite apparent that although some countries have adopted the SEZ regimes, critical issues are still missing which could be responsible for the concomitant challenges being experienced by SEZs in these countries. Failure to pay attention to the basic requirements for SEZs is bound to result in operational challenges. Generally, based on design attributes, this section identifies areas of concern with respect to SEZs in the case study countries.

\subsection{Organizational attributes}

The SEZ regimes were introduced without a specific policy or strategy in place in all the case study countries except South Africa and Namibia. This has the potential to create implementation challenges, especially when conflicts or overlaps occur with other government programmes on investments and incentives. In addition, Zambia does not have a stand-alone legislation on SEZs, and the SEZ regime is part of the general industrial promotion legislation. This suggests lack of prioritization of the SEZ programme; hence, it would achieve limited success. Having a standalone SEZ regulator makes it easier for the implementation and development of the SEZ. However, in Namibia and Zambia SEZ implementation is done by an industrial promotion body, also occupied with other matters pertaining to investment promotion and industrial promotion in general. This is expected to slow down SEZ programmes in these two countries. 
Given the importance of having SEZs fully developed before investors come in, some countries have also made the SEZ programme difficult by bestowing the SEZ development roles on the regulator. This is particularly true for Zimbabwe, Zambia, and Tanzania. As regulators, it is not likely that they would have the necessary expertise and capacity to develop the SEZs, hence the implementation of SEZ regimes in these three countries is likely to face operational challenges. There is need to ensure that the regulator only performs regulatory roles while the development of the SEZ is left to the developers and operators, as in South Africa and Mauritius.

\subsection{Economic factors}

The decision matrix for declaring an area an SEZ is very critical, as it determines the attractiveness of the SEZ to investors. The South Africa regime, which places the onus on the applicant to justify why the area has to be declared an SEZ as the only criteria for declaration, appears to be the best. For the rest of the countries, where the government can declare an area to be an SEZ on its own, criteria are bound to be dominated by political and not economic considerations. This implies that some areas that have been declared an SEZ might not be meeting the desired attributes; hence, they are not likely to succeed. Examples of SEZ areas where there are no backward or forward linkages with the rest of the economy or no apparent location advantages indicate that these could have been wrongly identified as suitable.

Embracing single-factory units into the SEZ regime also results in limited advantages, as the firms still lack the necessary enabling operating environment to perform. Tax incentives generally do not serve as the main reasons for SEZs to succeed. Besides tax incentives, single-factory units do not have other location advantages to exploit. Countries that have single-factory units in the SEZ regimes, such as Tanzania, Zimbabwe, and Namibia, have such firms still characterized by operational challenges due to enabling infrastructure and utility bottlenecks. A regime such as in South Africa, where the SEZ regime is strictly based on geographic delimitations, ensures that firms exploit the associated advantages.

\subsection{Physical/spatial factors}

Having conducive infrastructure in place before the SEZ becomes open to investors is the best way to ensure that the SEZ regime succeeds. However, only South Africa and now Mauritius (under the freeport zones) have ensured that SEZs can only operate after the requisite infrastructure is in place. The reason why some SEZs in Zambia, Zimbabwe, Namibia, and Tanzania have remained inactive despite having been designated as SEZs for a long time is mainly attributed to lack of the requisite infrastructure. There are two main problems with respect to infrastructure. First, off-site infrastructure, including electricity, water, and access to roads/rail facilities, requires utility providers to adequately prepare. Second, there is need for base infrastructure, which is normally the responsibility of the developer, to be in place before investors invest. However, while it is recorded that the SEZ regime is operational in all the six countries, those areas lacking both off-site and base infrastructure should ideally have not been opened up to investors. In some cases, the lack of infrastructure also relates to having no clear separate roles between regulators and developers, resulting in incapacitated regulators rushing to open up areas to investors.

\section{Recommendations}

SEZs are an important tool for promoting rapid economic growth, facilitating employment, and reducing poverty by attracting investment and technology. Countries that have done fairly well in 
paying attention to the design attributes of the SEZ, which include South Africa and Mauritius, stand a good chance of realizing these benefits. However, the other countries did not go the extra mile in ensuring that all the necessary design attributes to facilitate SEZ success are in place. It is therefore important to ensure that the following:

- The critical infrastructure that serves as enablers in SEZs should be prioritized. While governments have declared areas as SEZs, there is a tendency to expect investors to flock into these areas because of the tax incentives, when operations actually require enabling infrastructure. Governments need to ensure that infrastructure is adequately provided for before the zones begin to operate.

- Given the challenges of financing infrastructure development within the SEZs, countries that have imposed development roles in government entities should seek alternative methods of financing. This includes promoting and putting in place legislative and regulatory frameworks to facilitate public-private partnership arrangements in the provision of SEZ infrastructure.

- The SEZ regulatory bodies should not be given the mandate to develop SEZs, as it is a serious function requiring significant investment and expertise that the SEZ authorities lack. In addition, having an institution performing regulator and developer roles results in conflict of interest and compromising of the critical issues that developers need to observe.

- SEZ locations should be based on economic advantages to ensure sustainability and attractiveness to investors. The locations should be strategic to facilitate backward and forward linkages with downstream and upstream industries while also having a pull effect for other locations in the rest of the economy.

- Legislations governing SEZs should be tightened to ensure that the operation framework, roles, and responsibilities of all the SEZ institutions are clearly spelt out. The roles of the developer, operator, and regulator should be clear to ensure that the operational environment becomes predictable.

\section{References}

AllAfrica (2013). 'Zambia: Lumwana MFEZ Relocates'. Available at: https://allafrica.com/stories/201301180266.html (accessed 30 November 2019).

Alter, R.G. (1990). 'Export Processing Zones for Growth and Development: The Mauritian Example'. Working Paper WP/90/122. Washington DC: International Monetary Fund. Available at: https://www.elibrary.imf.org/view/IMF001/15345-9781451938869/153459781451938869/15345-9781451938869.xml?language $=$ en\&redirect $=$ true (accessed May 2020).

Ayadi, M., and W. Mattoussi (2014). 'Disentangling the Pattern of Geographic Concentration in Tunisian Manufacturing Industries’. WIDER Working Paper 2014/072. Helsinki: UNUWIDER. Available at: https://www.wider.unu.edu/sites/default/files/wp2014-072.pdf (accessed May 2020).

Boyenge J.S. (2007). 'ILO Database on Export Processing Zones'. Working Paper 251. Geneva: International Labour Organisation. Available at: https://ideas.repec.org/p/ilo/ilowps/993989593402676.html (accessed May 2020)

Cheong T.E. (2018). 'The Key Success Factors of Special Economic Zones'. Perspectives 28, Singapore: Surbana Jurong Group. Available at: https://surbanajurong.com/wpcontent/uploads/2018/06/Perspectives_28.pdf (accessed May 2020). 
COMCEC (2017). Special Economic Zones in the OIC Region: Learning from Experience. Ankara: COMCEC. Available at: http://www.sbb.gov.tr/wpcontent/uploads/2018/11/Special_Economic_Zones_in_the_OIC-Region.pdf (accessed May 2020).

Department of Trade and Industry (2012). 'Policy on the Development of Special Economic Zones in South Africa'. Government Gazette, 34968(January). Available at: https://www.gov.za/sites/default/files/gcis_document/201409/34968gen45.pdf (accessed May 2020).

Farole, T. (2011). Special Economic Zones in Africa: Comparing Performance and Learning from Global Experience. Washington, DC: World Bank. Available at: http:/ / documents.worldbank.org/curated/en/996871468008466349/pdf/600590PUB0ID 181onomic09780821386385.pdf (accessed May 2020).

Farole, T., C. Baissac, and J.-P. Gauthier (2013). Special Economic Zones: A Guidance Framework for Policymaking. Washington, DC: World Bank. Available at: https://static1.squarespace.com/static/54d667e5e4b05b179814c788/t/5bc6f862a4222f9ca 0735485/1539766376427/Farole-et-al-2013--SEZ+Policy+Framework-FinalDraft.pdf (accessed May 2020).

Government of Mauritius (2000). Investment Promotion Act No. 42 of 2000. Available at: http:/ / attorneygeneral.govmu.org/English/Documents/AZ\%20Acts/I/Page\%203/INVESTMENTPROMOTION1.pdf (accessed May 2020).

Government of Mauritius (2004). The Freeport Act 2004. Available at: https://www.mra.mu/download/FreeportAct2004.pdf (accessed May 2020).

Government of Namibia (1995). Export Processing Zones Act 9 of 1995. Available at: https://laws.parliament.na/cms_documents/export-processing-zones-b00056227f.pdf (accessed May 2020).

Government of Namibia (2016). Namibia Industrial Development Agency Act 16 of 2016. Available at: https://laws.parliament.na/cms_documents/namibia-industrial-developmentagency-ca5750ac00.pdf (accessed May 2020).

Government of Namibia (No date). Export Processing Zones (EPZ) Industrial Development Strategy: Investor Guide. Available at: http://www.mti.gov.na/downloads/Namibias\%20Export\%20Processing\%20Zone.pdf (accessed May 2020).

Government of South Africa (2014). Special Economic Zones Act 16 of 2014. Available at: https://www.gov.za/documents/special-economic-zones-act (accessed May 2020).

Government of Tanzania (2002). Export Processing Zones Act, 2002. Available at: https://www.ilo.org/dyn/natlex/docs/ELECTRONIC/64746/61562/F230060879/TZA6 4746.pdf (accessed May 2020).

Government of Tanzania (2006). Special Economic Zones Act, 2006. Available at: https://www.ilo.org/dyn/natlex/docs/ELECTRONIC/75398/78436/F2058015963/TZA 75398.pdf (accessed May 2020).

Government of Tanzania (2011). The Economic Zones Laws (Miscellaneous Amendments) Act, 2011.

https://www.ilo.org/dyn/natlex/docs/ELECTRONIC/90404/104191/F1493307622/TZ A90404.pdf (accessed May 2020). 
Government of Zambia (2006). Zambia Development Agency Act Number 11 of 2006. Available at: http://ilo.org/dyn/natlex/docs/ELECTRONIC/90114/103666/F1295800516/ZMB90114.pdf (accessed May 2020).

Government of Zambia (2007). Multi-Facility Economic Zones (General) Regulations of 2007. Available at: https://zambialii.org/zm/legislation/statutory-instrument/2007/65 (accessed May 2020).

Government of Zimbabwe (2016). Special Economic Zones Act [Chapter 14:34] of 2016. Available http://www.veritaszim.net/sites/veritas_d/files/Special\%20Economic\%20Zones\%20Act \%20\%5BChapter\%2014-34\%5D.pdf (accessed May 2020).

Government of Zimbabwe (2018). Special Economic Zones (General) Regulations of 2018. Available http://www.veritaszim.net/sites/veritas_d/files/SI\%20154\%20of\%202018.pdf (accessed May 2020).

Kinyondo, A., C. Newman, and F. Tarp (2016). 'The Role and Effectiveness of Special Economic Zones in Tanzania'. WIDER Working Paper 2016/122. Helsinki: UNU-INTECH. Available at: https://www.econstor.eu/bitstream/10419/161505/1/872463915.pdf (accessed May 2020).

Kolko, J., and D. Neumark (2009). 'Do Some Enterprise Zones Create Jobs?' NBER Working Paper 15206. Cambridge, MA: NBER. Available at: https://www.nber.org/papers/w15206.pdf (accessed May 2020).

Kweka, J. (2018). 'Harnessing Special Economic Zones to Support Implementation of Tanzania's Five-Year Development Plan 2016/17-2020/21'. Supporting Economic Transformation Programme. London: Overseas Development Institute. Available at: https://set.odi.org/wpcontent/uploads/2018/11/Harnessing-SEZs-in-Tanzania_JKweka_Final.pdf (accessed May 2020).

Namibia Investment Centre, Ministry of Trade and Industry, and Offshore Development Company (No date). 'Export Processing Zone (EPZ) Industrial Development Strategy, Harnessing Namibia's Manufacturing and Exporting Potential: Investor Guide'. Available at: at: http://www.mti.gov.na/downloads/Namibias\%20Export\%20Processing\%20Zone.pdf (accessed 30 November 2019).

Newman C., and J. Page (2017). 'Industrial Clusters: The Case for Special Economic Zones in Africa'. Working Paper 2017/15. Helsinki: UNU-WIDER. Available at: https://www.wider.unu.edu/sites/default/ files/wp2017-15.pdf (accessed May 2020).

Nyakabawo, W. (2014). 'The Geographic Designation of Special Economic Zones'. TIPS Working Paper. Pretoria: Trade and Industrial Policy Strategies (TIPS). Available at: http://www.tips.org.za/files/special_economic_zones_november_2014.pdf (accessed May 2020).

OECD (2017). Tracking Special Economic Zones in the Western Balkans: Objectives, Features and Key Challenges. Paris: Organisation for Economic Co-operation and Development (OECD). Available at: http://www.oecd.org/south-east-europe/SEZ_WB_2017.pdf (accessed May 2020).

Sanspeur, G., and R. Chellapermal (1996). 'Freeport Development: The Mauritius Experience'. In: UNCTAD and International Association of Ports and Harbors (eds), UNCTAD Monographs on Port Management. New York and Geneva: UNCTAD. Available at: http://nationallibrary.govmu.org/English/Documents/Digit-Coll/dig5.pdf (accessed May 2020). 
SEZ Advisory Board (2018). Annual Report 2017/18. Pretoria: Department of Trade and Industry.

Siba, E., M. Söderbom, A. Bigsten, and M. Gebreeyesus (2012). 'Enterprise Agglomeration, Output Prices, and Physical Productivity: Firm-Level Evidence from Ethiopia'. WIDER Working Paper 2012/085. Helsinki: UNU-WIDER. Available at: https://www.wider.unu.edu/sites/default/files/wp2012-085.pdf (accessed May 2020).

Sinenko, O., and I. Mayburov (2017). 'Comparative Analysis of the Effectiveness of Special Economic Zones and Their Influence on the Development of Territories'. International Journal of Economics and Financial Issues, 7(1): 115-22.

UNCTAD (2019). 'Special Issue on Special Economic Zones'. Transnational Corporations, 26(2). United Nations Conference on Trade and Development (UNCTAD). Available at: https://unctad.org/en/pages/PublicationWebflyer.aspx?publicationid=2518 (accessed May 2020).

UNDP (2015). 'If Africa Builds Nests, Will the Birds Come? Comparative Study on Special Economic Zones in Africa and China'. Working Paper Series 06, 2015. Beijing: UNDP. Available at: https://www.undp.org/content/dam/china/docs/Publications/UNDP-CHComparative $\% 20$ Study $\% 20$ on $\% 20$ SEZs $\% 20$ in $\% 20$ Africa $\% 20$ and $\% 20$ China $\% 20$ \%20ENG.pdf (accessed May 2020).

World Bank (2016). 'Multi-facility Economic Zones in Zambia: Progress, Challenges and Possible Interventions'. Working Paper. Washington, DC: World Bank. Available at: http:/ / documents.worldbank.org/curated/en/720981495115586647/pdf/115143-WPPUBLIC-Feb-2016-GTCCS-ZambiaMFEZ.pdf (accessed May 2020).

World Bank (2017). Special Economic Zones: An Operational Review of Their Impacts. Washington, DC: World Bank. Available at: http://documents.worldbank.org/curated/en/316931512640011812/pdf/P154708-12-072017-1512640006382.pdf (accessed May 2020).

WTO (2019). 'Trade Policy Review Report by the Secretariat: East African Community'. Annexure 4: Tanzania, WT/TPR/S/384. World Trade Organisation. Available at: https://www.wto.org/english/tratop_e/tpr_e/s384-04_e.pdf (accessed May 2020).

Zambia Development Agency (No date). Multi-Facility Economic Zone. Available at: http://www.zda.org.zm/?q=content/multi-facility-economic-zone-mfez (accessed 30 November 2019).

Zeng D.Z. (2016). 'Special Economic Zones: Lessons from the Global Experience'. PEDL Synthesis Paper Series 1. Available at: https://pedl.cepr.org/publications/special-economiczones-lessons-global-experience (accessed May 2020). 